\title{
Multicystic dysplastic kidney and related epidemiologic factors
}

\author{
Parsa Yousefichaijan ${ }^{1}$, Fereshte Maghsudlu ${ }^{2 *}$, Mohammad Rafiei ${ }^{3}$ \\ ${ }^{1}$ Infectious Disease Research Center (IDRC), Department of Pediatric Nephrology, Faculty of Medicine, Arak University of Medical \\ Sciences, Arak, Iran \\ ${ }^{2}$ Students Research Committee, Faculty of Medicine, Arak University of Medical Sciences, Arak, Iran \\ ${ }^{3}$ Department of Biostatistics, Faculty of Medicine, Arak University of Medical Sciences, Arak, Iran
}

\section{ART I CLE IN F O}

\section{Article Type:}

Original

\section{Article History:}

Received: 14 January 2017

Accepted: 22 May 2017

Published online: 20 June 2017

\section{Keywords:}

Multicystic dysplastic kidney

Epidemiologic factors

Children

\begin{abstract}
A B S T R A C T
Introduction: Multicystic dysplastic kidney (MCDK) is a sporadic developmental abnormality caused by abnormal differentiation of the metanephric that is present as a flank mass in infancy. It may lead to renal dysfunction or death as a result of oligohydramnios or respiratory failure.

Objectives: This research had aimed to find a probable related link between the MCDK and epidemiologic factors.

Patients and Methods: A total of 120 children were evaluated in this case-control research. The case and control groups included 60 children with MCDK and 60 children without MCDK, respectively. Examinations, interviews and questionnaires carried out by the project and diagnosis by a physician. We analyzed our results data using chi-square and student $t$ test as appropriate.

Results: The result of this study did not show significant relationship between epidemiological factors such as age, place of residence for families, sex, family education/occupation/ income, body mass index (BMI), stunted growth, slow growth, good growth, milk intake, water intake, failure to thrive (FTT) and MCDK.

Conclusion: This study showed that epidemiological factors do not have a significant effect on the occurrence of MCDK disease.
\end{abstract}

Implication for health policy/practice/research/medical education:

Better understanding of conditions that predispose MCDK could be a critical step towards improving clinical consequence and management of this disease. Since there is little evidence on the relationship between MCDK and epidemiologic factors, we evaluated this relationship hypothesizing that these epidemiologic conditions would increase the risk of MCDK.

Please cite this paper as: Yousefichaijan P, Maghsudlu F, Rafiei M. Multicystic dysplastic kidney and related epidemiologic factors. J Renal Inj Prev. 2017;6(3):236-239. DOI: 10.15171/jrip.2017.44.

\section{Introduction}

A multicystic dysplastic kidney (MCDK) is the outcome of atypical metanephric differentiation. This is the second most prevalent disease that present with flank mass in neonate. The frequency rate is 1 in 4300. A true multicystic kidney is usually sporadic, inherited abnormality and is not associated with other abnormalities in other parts of the body. It can be diagnosed during pregnancy by prenatal ultrasonography or by finding an abdominal mass, or by the evaluation of a urinary tract infection (1). MCDK as a variant of renal dysplasia, identified by structural disorganization of the kidney with primitive epithelium and undeveloped ducts $(2,3)$, leads to the different form of aplasia and hypoplasia. In this disease there are numerous cysts in kidney which are separated by parenchyma (3), and result in a grape like collection of cysts without saving of normal kidney structure and performance (3, 4). The exact mechanism of development of MCDK is not approved, but suggested assumption includes atypical creation of the metanephrogenic diverticulum and/or abnormal communication between the metanephrogenic diverticulum and metanephric mesenchyme, viral infections and drugs as a teratogen agents, and fetal urinary tract obstruction $(3,5)$. MCKD is usually correlated with different abnormalities of the kidneys and urinary tract (6-8), including vesicoureteral reflux 
(VUR), obstruction at the ureterovesical junction (UVJ) and the ureteropelvic junction (UPJ) $(7,8)$. Managing the unilateral MCDK is conservative in neonates. After the diagnosis with ultrasound, DMSA, and cystography should be done to determine malfunction in the MCDK and rule out the VUR in the other kidney (8-10). Most of the patients are now treated without operation. Patients should be examined regularly in the clinic to monitor progression of the MCDK and evaluating the other kidney conditions $(8,9)$. If MCDK involves both kidneys it will lead to renal nonfunction of fetus and neonate which results in pulmonary hypoplasia with its complications for life $(11,12)$. Although, MCDK in one kidney is an abnormality that is not generally associated with any sign or symptom, except for large flank masses in abdomen, it may be led to difficult natural vaginal delivery $(12,13)$.

\section{Objectives}

We intend to do this research to find the probable relationship between MCDK and epidemiologic risk factors, with this theory that these epidemiologic conditions would increase the risk of MCDK.

\section{Patients and Methods}

We surveyed epidemiologic characteristics of children that had been visited in pediatrics and urology clinics of Amirkabir hospital, Arak, Iran. To assess the association of MCDK and epidemiologic factors, epidemiologic characteristics were 1) age at diagnosis of MCDK, 2) gender (male and female), 3) family education (below high school, high school diploma, bachelor's degree and master's degree), 4) family occupation (employee, worker, self-employment and housewife for mothers), 5) average monthly salary of family $(<300,300-600$ and $>600 \$), 6)$ drinking water (tap water or purified water with household devices) ,7) failure to thrive (FTT), 8) stunted growth, 9) slow growth, 10) good growth, 11) milk intake (maternal milk or powdered milk), 12) infant BMI $\left(\mathrm{kg} / \mathrm{m}^{2}\right)(<18.5$, 18.5-24.9, 25-29.9 and >30), 13) place of residence in urban or rural areas and 14) gestational week (preterm $<37$, term $37-42$, and post-term $>42$.

\section{Ethical issues}

This article is based on the tenets of the Declaration of Helsinki; informed consent was obtained, and the research was approved by ethics committee of Arak University of Medical Sciences.

\section{Statistical analysis}

The results were analyzed by SPSS software, version 18.00, using students $t$ test, and the chi-square test as appropriately, based on the data that were continuous or not. A $P<0.05$ was considered to indicate statistical significance.

\section{Results}

The mean age of studied infants was 9 months of age at the time of MCDK diagnosis. There was not a predominance of one gender among cases and controls. (65\% girls in cases). The distribution of all studied epidemiologic factors were similar in case and control groups (Table 1). Concerning growth status, FTT was not observed in cases or controls. Stunted growth was found in $18.3 \%$ of cases and controls $(P>0.05)$. Around $28.3 \%$ of cases and $26.6 \%$ of controls had slow growth $(P=0.978), 55 \%$ of cases and $58.3 \%$ of controls had good growth $(P=0.978) .85 \%$ of cases and $81.6 \%$ controls were fed with maternal milk $(P=0.877)$. $90 \%$ of cases and $91.6 \%$ of controls lived in urban areas $(P=0.927) .90 \%$ of cases and $88.3 \%$ of controls drank tap water $(P=0.965)$.

\section{Discussion}

Based on the our study, we found no significant difference between the two groups. The distributions of all studied risk factors were alike in cases and controls. Up to now, no study has been conducted on the correlation between MCDK and epidemiologic factors in children. However, different studies have been conducted on related risk factors in children with various stage of chronic kidney disease. According to the earlier studies low-birth weight and maternal pre-gestational diabetes mellitus have

Table 1. Epidemiologic characteristics of study group

\begin{tabular}{|c|c|c|}
\hline Epidemiologic factors & $\begin{array}{c}\text { Case } \\
\text { No. (\%) } \\
\end{array}$ & $\begin{array}{l}\text { Control } \\
\text { No. (\%) } \\
\end{array}$ \\
\hline \multicolumn{3}{|l|}{ Father's education } \\
\hline Below high school & $4(6.6)$ & $3(6.6)$ \\
\hline High school diploma & $26(43.3)$ & $29(48.3)$ \\
\hline Bachelor's degree & $23(38.3)$ & $21(35)$ \\
\hline Master's degree and more & $7(11.6)$ & $7(11.6)$ \\
\hline \multicolumn{3}{|l|}{ Mother's education } \\
\hline Below high school & $7(11.6)$ & $7(11.6)$ \\
\hline High school diploma & $27(45)$ & $27(45)$ \\
\hline Bachelor's degree & $25(41.6)$ & $25(41.6)$ \\
\hline Master's degree and more & $1(1.6)$ & $1(1.6)$ \\
\hline \multicolumn{3}{|l|}{ Father's occupation } \\
\hline Employee & $26(43.3)$ & $24(40)$ \\
\hline Worker & $26(43.3)$ & $30(50)$ \\
\hline Self-employment & $8(13.3)$ & $6(10)$ \\
\hline \multicolumn{3}{|l|}{ Mother's occupation } \\
\hline Employee & $18(30)$ & $16(0.26)$ \\
\hline Worker & $9(15)$ & $7(11.6)$ \\
\hline Self-employment & $10(16.6)$ & $10(16.6)$ \\
\hline Housewife & $23(38.3)$ & $27(45)$ \\
\hline \multicolumn{3}{|c|}{ Average monthly salary of family } \\
\hline$<300 \$$ & $5(8.3)$ & $3(5)$ \\
\hline $300-600 \$$ & $29(48.3)$ & $36(60)$ \\
\hline$>600 \$$ & $26(43.3)$ & $21(35)$ \\
\hline \multicolumn{3}{|l|}{ Gestational age } \\
\hline Preterm & $14(23.3)$ & $17(28.3)$ \\
\hline Term & $45(75)$ & $43(71.6)$ \\
\hline Post term & $1(1.6)$ & $0(0)$ \\
\hline \multicolumn{3}{|l|}{ Infant BMI } \\
\hline$<18.5$ & $6(10)$ & $5(8.3)$ \\
\hline $18.5-24.9$ & $35(58.3)$ & $33(55)$ \\
\hline $25-29.9$ & $13(21.6)$ & $15(25)$ \\
\hline$>30$ & $6(10)$ & $7(11.6)$ \\
\hline
\end{tabular}


significant association with an increased risk of renal dysplasia/aplasia. Low birth weight, maternal DM during pregnancy and maternal high BMI were significantly associated with obstructive uropathy. The data suggests that antenatal conditions may influence the incidence of CKD (14). Chen et al concluded that diabetes during pregnancy may increase the risk of nephron insufficiency that finally lead to the development of hypertension in future. Based on evidence diabetes during pregnancy predisposes antenatal development of hypertension, kidney disease, and glucose intolerance in the children(15). Al Salmi et al studied birth weight in patients with CKD, the data demonstrated that low birth weight is related with CKD and its stage. The possible reason is the reported relationship between birth weight and glomerular count (16). Birth weight could influence glomerular filtration rate (GFR). There is a documented relationship of birth weight with nephron characteristics (17). About 70\% of CKD in children is due to inborn renal abnormalities and urinary tract (18). Prenatal factors may affect the risk of infantile reflux nephropathy. The results showed that age more than 35 years, chronic hypertension, preeclampsia and eclampsia, preterm delivery, very low birth weight (VLBW), chronic DM, and maternal body mass index $<18.5 \mathrm{~kg} / \mathrm{m}^{2}$ (underweight) were prenatal risk factors for infantile reflux nephropathy (19).

\section{Conclusion}

The documents on the correlation of MCDK and epidemiologic factors are few. We desire that our study will serve as an impetus to more prospective studies to determine the predisposing conditions and clinical consequences of children with MCDK with the aim of studying the pathophysiology due to improve management of MCDK and to evaluate even if adjustment of these condition can influence the frequency of MCDK. As mentioned, earlier studies showed that there are some prenatal conditions that increase the frequency of renal disease and CKD. Probably the differences between some of the items in our study and others is due to the higher statistical population and a more general definition of CKD than MCDK.

\section{Limitations of the study}

A limitation of our study was small proportion of patients. We suggest multi-centric studies on this aspect of kidney disease.

\section{Acknowledgments}

The authors gratefully acknowledge the Research Council of Arak University of Medical Sciences for the financial support.

\section{Authors' contribution}

PY contributed to the arrangement of the study, conducted the data collecting, and served as the lead author of the manuscript. MR wrote some parts of the draft. FM participated in the arrangement of the study, conducted the statistical analysis, and finalized the manuscript. All authors read and approved the final manuscript.

\section{Conflicts of interest}

The authors declared no competing interests.

\section{Ethical considerations}

Ethical issues (including plagiarism, data fabrication, double publication) have been completely observed by the authors.

\section{Funding/Support}

This study was supported by a grant (No. 2388) from the Arak University of Medical Sciences.

\section{References}

1. Kaplan BS, Meyers KE. Pediatric Nephrology and Urology: The Requisites in Pediatrics. Philadelphia, PA: Mosby; 2004.

2. Kuwertz-Broeking E, Brinkmann O, Von Lengerke HJ, Sciuk J, Fruend S, Bulla M, et al. Unilateral multicystic dysplastic kidney: experience in children. BJU Int. 2004;93:388-92. doi: 10.1111/j.1464-410X.2003.04623.x.

3. Verghese P, Miyashita Y. Neonatal polycystic kidney disease. 2014;41:543-60. doi: 10.1016/j.clp.2014.05.005.

4. Greene L, Feinzaig W, Dahlin D. Multicystic dysplasia of the kidney: with special reference to the contralateral kidney. J Urol. 1971;105:482-7.

5. Hains DS, Bates CM, Ingraham S, Schwaderer AL. Management and etiology of the unilateral multicystic dysplastic kidney: a review. Pediatr Nephrol. 2009;24:23341. doi: 10.1007/s00467-008-0828-8.

6. Atiyeh B, Husmann D, Baum M. Contralateral renal abnormalities in multicystic-dysplastic kidney disease. J Pediatr. 1992;121:65-7. doi: 10.1016/S00223476(05)82543-0

7. Mansoor O, Chandar J, Rodriguez MM, Abitbol CL, Seeherunvong W, Freundlich M, et al. Long-term risk of chronic kidney disease in unilateral multicystic dysplastic kidney. Pediatr Nephrol. 2011;26:597-603. doi: 10.1007/ s00467-010-1746-0.

8. Shaheen IS, Watson AR, Broderick N, Rance C. Multicystic dysplastic kidney and pelviureteric junction obstruction. Pediatr. Surg Int. 2005;21:282-4. doi: 10.1007/s00383-0041303-7.

9. Sukthankar S, Watson A. Unilateral multicystic dysplastic kidney disease: defining the natural history. Anglia Paediatric Nephrourology Group. Acta Paediatr Suppl. 2000;89:811-3. doi: 10.1080/080352500750043701.

10. Watson A. Management of antenatally detected urinary tract abnormalities. Paediatr Child Health (Oxford). 1999;9:232-6. doi: 10.1054/cupe.1999.0052.

11. Damen-Elias H, De Jong T, Stigter R, Visser G, Stoutenbeek P. Congenital renal tract anomalies: outcome and follow-up of 402 cases detected antenatally between 1986 and 2001 . Ultrasound Obstet Gynecol. 2005;25:134-43. doi: 10.1002/ uog. 1788 .

12. Schreuder MF, Westland R, van Wijk JA. Unilateral multicystic dysplastic kidney: a meta-analysis of observational studies on the incidence, associated urinary tract malformations and the contralateral kidney. Nephrol Dial Transplant. 2009;24:1810-8. doi: 10.1093/ndt/gfn777.

13. Triest JA, Bukowski TP. Multicystic dysplastic kidney 
as cause of gastric outlet obstruction and respiratory compromise. J Urol. 1999;161:1918-9. doi: 10.1016/S00225347(05)68852-0.

14. Hsu CW, Yamamoto KT, Henry RK, De Roos AJ, Flynn JT. Prenatal risk factors for childhood CKD. Clin J Am Soc Nephrol. 2014;25:2105-11. doi: 10.1681/ASN.2013060582

15. Chen Y-W, Chenier I, Tran S, Scotcher M, Chang S-Y, Zhang S-L. Maternal diabetes programs hypertension and kidney injury in offspring. Pediatr Nephrol. 2010;25:131929. doi: 10.1007/s00467-010-1506-1.

16. Al Salmi I, Hoy WE, Kondalsamy-Chennakes S, Wang Z, Healy H, Shaw JE. Birth weight and stages of CKD: a casecontrol study in an Australian population. Am J Kidney
Dis. 2008;52:1070-8. doi: 10.1053/j.ajkd.2008.04.028.

17. Al Salmi I, Hoy W, Kondalsamy-Chennakesavan S, Wang Z, Atkins R, Barr E, et al. P1-95 Lower glomerular filtration rate in adults with low birthweight: results from the AusDiab study. Early Hum Dev. 2007;83:S109. doi: 10.1016/ S0378-3782:70265-7.

18. Mak RH, Schaefer F. Chronic kidney disease: Prenatal risk factors for kidney and urinary tract anomalies. Nat Rev Nephrol. 2014;10:428-9. doi: 10.1038/nrneph.2014.105.

19. Yousefichaijan P, Safi F, Rafiei M, Taherahmadi H, Fatahibayat GA, Naziri M. Prenatal Risk Factors for Infantile Reflux Nephropathy. J Ped Nephrol. 2015;3:135-8.

Copyright () 2017 The Author(s); Published by Nickan Research Institute. This is an open-access article distributed under the terms of the Creative Commons Attribution License (http://creativecommons.org/licenses/by/4.0), which permits unrestricted use, distribution, and reproduction in any medium, provided the original work is properly cited. 